\title{
Are heterogenous results of EGFR immunoreactivity in renal cell carcinoma related to non-standardised criteria for staining evaluation?
}

\author{
C Langner, M Ratschek, P Rehak, L Schips, R Zigeuner
}

J Clin Pathol 2004;57:773-775. doi: 10.1136/icp.2003.015743

\begin{abstract}
Aims: To assess whether heterogeneity of epidermal growth factor receptor (EGFR) immunoreactivity in renal cell carcinoma (RCC) is related to non-standardised criteria for staining evaluation.

Methods: EGFR expression was investigated in 132 primary and 55 metastatic conventional RCCs using a tissue microarray technique.

Results: Overall, membranous and/or cytoplasmic EGFR immunostaining was present in 123 of $132(93 \%)$ primary and 49 of $53(92 \%)$ metastatic RCCs, with extensive immunoreactivity ( $>50 \%$ of tumour cells) in 110 of 132 (83\%) primary tumours and 39 of $53(73 \%)$ metastases. Cytoplasmic staining was associated with high tumour stage and high tumour grade. In addition, strong membranous staining (score $3+$ ) prevailed in high grade RCCs. Cytoplasmic immunostaining was associated with an unfavourable prognosis, whereas overall (cytoplasmic and membranous) immunoreactivity and intensity of membranous staining were not.

Conclusions: Different methods of immunohistochemical evaluation led to different results, strengthening the need for standardisation, especially against a background of rapidly evolving EGFR targeted cancer treatment strategies.
\end{abstract}

$\mathrm{T}$ he epidermal growth factor receptor (EGFR) belongs to a family of four closely related cell membrane receptors: EGFR (HER1; ErbB1), HER2 (ErbB2), HER3 (ErbB3), and HER4 (ErbB4). These receptors are transmembrane glycoproteins with an extracellular ligand binding domain and an intracellular domain with tyrosine kinase activity involved in signal transduction. EGFR activation leads to cell cycle progression, inhibition of apoptosis and angiogenesis, promotion of invasion/metastasis, and other tumour promoting activities. ${ }^{1}$ EGFR overexpression has been correlated with an aggressive clinical course in a variety of cancers. ${ }^{1}$ Renal cell carcinomas (RCCs) frequently display EGFR immunoreactivity. However, data in the literature with respect to associations with tumour stage/grade and prognostic impact are conflicting. ${ }^{2-7}$

"Epidermal growth factor receptor activation leads to cell cycle progression, inhibition of apoptosis and angiogenesis, promotion of invasion/metastasis, and other tumour promoting activities"

In our study, we used three different methods to analyse EGFR expression in a large number of primary and metastatic conventional RCCs and correlated the results with pT stage, tumour grade, and disease free survival.

\section{MATERIALS AND METHODS}

Paraffin wax embedded specimens from 132 primary conventional (clear cell) RCCs and 53 unrelated conventional RCC metastases were selected for analysis. The pT stages of the primary tumours were assessed according to the UICC 2003 issue of the TNM system and the nuclear grades were assessed according to the Fuhrman grading system. For immunohistochemistry, a tissue microarray technique was used that included three cylindrical core biopsies $(0.6 \mathrm{~mm}$ in diameter) taken from different sites of each tumour. ${ }^{8}$ EGFR immunoreactivity was investigated using the EGFR pharmDx $^{\mathrm{TM}}$ kit (DakoCytomation, Glostrup, Denmark). Membranous and/or cytoplasmic staining was considered positive and the total percentage of tumour cells stained was categorised as either "focal" $(+;<10 \%$ of tumour cells positive), "moderate" (++; 10-50\% positive), or "extensive" $(+++>50 \%$ positive $)$. In another step, only the cytoplasmic staining was assessed according to the same criteria. Finally, the intensity of membranous immunostaining was categorised as either "weak" (score 1+), "moderate" (score 2+), or "strong" (score 3+). For statistical analysis, subgroups according to pT category, grade, and histological subtype were compared using the $\chi^{2}$ test or Fisher's exact test, respectively. Disease free survival in conventional cancers was investigated using the Kaplan-Meier method and compared by the log rank test. Cox's proportional hazards regression model was used for multivariate testing.

\section{RESULTS}

Overall, membranous and/or cytoplasmic EGFR immunostaining was present in 123 of $132(93 \%)$ primary and 49 of $53(92 \%)$ metastatic conventional RCCs with extensive immunoreactivity in 110 of $132(83 \%)$ primary tumours and 39 of $53(74 \%)$ metastases. No associations with pT stages or tumour grades were found. However, cytoplasmic EGFR staining alone was associated with rising tumour grade $(\mathrm{Gl} / 2,48$ of $84 ; \mathrm{G} 3 / 4,40$ of $48 ; \mathrm{p}=0.002)$ and stage (pTl/2, 41 of 71 ; pT3, 47 of $61 ; p=0.026$; fig 1A, B). Moreover, strong membranous staining (score $3+$ ) was more frequently seen in high grade tumours (G1, five of 16; G2, 41 of 68; G34 , 34 of $48 ; \mathrm{p}=0.019$; table 1 ). No association between intensity of membranous staining and pT stages was found.

Follow up data were available for 127 of 132 (96\%) patients with primary RCCs. After a median follow up of 24 months disease progression was seen in 29 of 127 (23\%) patients, including 15 patients who died from cancer and 14 patients who are currently alive with metastatic disease. Regarding overall EGFR immunoreactivity and intensity of membranous staining, no associations with prognosis were found. However, cytoplasmic EGFR immunostaining was associated

Abbreviations: EGFR, epidermal growth factor receptor; RCC, renal cell carcinoma 

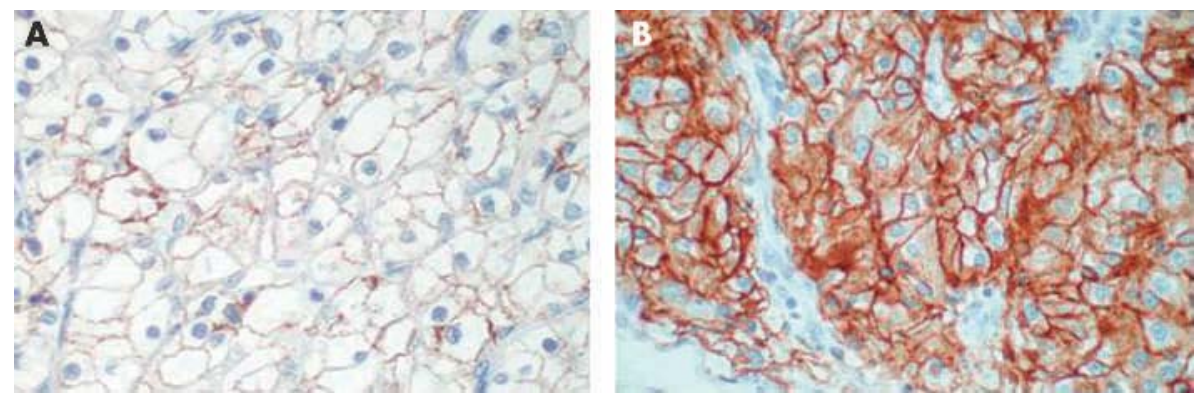

Figure 1 Epidermal growth factor receptor immunostaining in conventional renal cell carcinoma. (A) Weak to moderate membranous staining in a well differentiated tumour and (B) strong membranous and diffuse cytoplasmic immunoreactivity in a poorly differentiated tumour.

with disease free survival because 26 of 86 patients with RCCs showing cytoplasmic immunoreactivity developed progressive disease, compared with three of 41 patients without cytoplasmic staining $(\mathrm{p}<0.001)$. Multivariate analysis, however, proved pT stages $3 \mathrm{a} / 3 \mathrm{~b}$ (risk ratio, 3.5; $\mathrm{p}=0.026$ ) and grades $3 / 4$ (risk ratio, $16.7 ; \mathrm{p}<0.001$ ) to be the only independent prognostic markers, whereas for cytoplasmic EGFR staining only a trend was noted (risk ratio, $3.3 ; \mathrm{p}=0.07)$.

\section{DISCUSSION}

Renal cancer is known to be largely resistant to conventional chemotherapy. ${ }^{9}$ The frequent expression of EGFR in RCCs in our series, which was shown for the first time both in primary and in metastatic tumour tissues, makes this type of cancer a promising candidate for EGFR targeted tumour treatment. ${ }^{1}$ However, the identification of those patients who might benefit from this treatment currently relies on non-standardised criteria for the interpretation of EGFR immunostaining. In our study, three different methods of immunohistochemical evaluation, which were all part of the "pathology report form" recommended by the manufacturer of the detection kit used, were applied and shown to yield

Table 1 Membranous and/or cytoplasmic EGFR immunoreactivity and intensity of membranous staining in RCC, in addition to the relation between strong membranous EGFR immunostaining and PT category and tumour grade

\begin{tabular}{|c|c|c|}
\hline & \multicolumn{2}{|c|}{ Conventional RCCs ( $n=132$ ) } \\
\hline & $\mathbf{N}$ & $\%$ \\
\hline \multicolumn{3}{|c|}{ Overall immunoreactivity } \\
\hline Negative & 9 & 7 \\
\hline+ & 2 & 2 \\
\hline ++ & 11 & 8 \\
\hline +++ & 110 & 83 \\
\hline \multicolumn{3}{|c|}{ Membranous staining } \\
\hline Score 0 & 10 & 8 \\
\hline Score $1+$ & 18 & 14 \\
\hline Score $2+$ & 24 & 18 \\
\hline Score 3+ & 80 & 61 \\
\hline \multicolumn{3}{|l|}{ Stage } \\
\hline pTla & $24 / 45$ & 53 \\
\hline pTIb & $15 / 21$ & 71 \\
\hline рT2 & $2 / 5$ & 40 \\
\hline рT3a & $16 / 27$ & 59 \\
\hline рT3b & $23 / 34$ & 68 \\
\hline \multicolumn{3}{|l|}{ Grade } \\
\hline G1 & $5 / 16$ & 31 \\
\hline G2 & $41 / 68$ & 60 \\
\hline G3 & $31 / 44$ & 70 \\
\hline G4 & $3 / 4$ & 75 \\
\hline
\end{tabular}

different results with respect to associations with tumour stage and grade, in addition to the patients' outcome.

"Future studies should be aimed at answering the question of whether different patterns of immunoreactivity (membranous versus cytoplasmic) might help select patients for different approaches of epidermal growth factor receptor targeted treatment"

Thus, our results may explain the conflicting data in the literature: some studies showed an association of EGFR immunoreactivity with well differentiated RCCs, ${ }^{2}$ or regarded strong membranous EGFR immunostaining as an indicator of good prognosis, ${ }^{3}$ whereas others showed an association of EGFR immunoreactivity with high tumour stage/grade and poor prognosis, ${ }^{4}{ }^{7}$ or no significant associations at all. ${ }^{56}$

Surgical pathologists are currently faced with growing clinical requests regarding EGFR immunostaining in several types of cancer. However, to provide a reliable basis for a tailored cancer treatment a standardisation of the criteria for the evaluation of EGFR immunostaining is indispensable. Moreover, future studies should be aimed at answering the question of whether different patterns of immunoreactivity (membranous versus cytoplasmic) might help select patients for different approaches of EGFR targeted treatment ${ }^{1}$ - for example, monoclonal antibodies that interfere with cell membrane receptor proteins or specific low molecular weight inhibitors of intracellular tyrosine kinases.

\section{Take home messages}

- Membranous and/or cytoplasmic epidermal growth factor (EGFR) immunostaining was seen in $93 \%$ of primary and $92 \%$ of metastatic renal cell carcinoma (RCCs), with extensive immunoreactivity in $83 \%$ of primary tumours and $73 \%$ of metastases

- Cytoplasmic immunostaining was associated with high tumour stage and high tumour grade and strong membranous immunostaining (score $3+$ ) was seen in high grade RCCs

- Cytoplasmic immunostaining was associated with an unfavourable prognosis, whereas overall (cytoplasmic and membranous) immunoreactivity and intensity of membranous staining were not

- Different methods of immunohistochemical evaluation led to different results, strengthening the need for standardisation, especially with the emergence of EGFR targeted cancer treatment strategies 


\section{Authors' affiliations}

C Langner, M Ratschek, Institute of Pathology, Medical University of Graz, Auenbruggerplatz 25, A-8036 Graz, Austria

P Rehak, Department of Surgery, Division of Biomedical Engineering and Computing, Medical University of Graz

L Schips, R Zigeuner, Department of Urology, Medical University of Graz

Correspondence to: $\operatorname{Dr} C$ Langner, Institute of Pathology, Medical University of Graz, Auenbruggerplatz 25, A-8036 Graz, Austria; cord. langner@meduni-graz.at

Accepted for publication 12 February 2004

\section{REFERENCES}

1 Mendelsohn J, Baselga J. Status of epidermal growth factor receptor antagonists in the biology and treatment of cancer. $J$ Clin Oncol 2003;21:2787-99.
2 Hofmockel G, Riess S, Bassukas ID, et al. Epidermal growth factor family and renal cell carcinoma: expression and prognostic impact. Eur Urol 1997;31:478-84

3 Kallio JP, Hirvikoski P, Helin $\mathrm{H}$, et al. Membranous location of EGFR immunostaining is associated with good prognosis in renal cell carcinoma. Br J Cancer 2003;89:1266-9.

4 Lager DJ, Slagel DD, Palechek PL. The expression of epidermal growth factor receptor and transforming growth factor alpha in renal cell carcinoma. Mod Pathol 1994:7:544-8.

5 Moch H, Sauter G, Buchholz N, et al. Epidermal growth factor receptor expression is associated with rapid tumor cell proliferation in renal cell carcinoma. Hum Pathol 1997;28:1255-9.

6 Moch H, Sauter G, Gasser TC, et al. EGF-r gene copy number changes in renal cell carcinoma detected by fluorescence in situ hybridization. J Pathol 1998; 184:424-9.

7 Uhlman DL, Nguyen P, Manivel JC, et al. Epidermal growth factor receptor and transforming growth factor $\alpha$ expression in papillary and nonpapillary renal cell carcinoma: correlation with metastatic behaviour and prognosis. Clin Cancer Res 1995;1:913-20.

8 Kononen J, Bubendorf L, Kallioniemi A, et al. Tissue microarrays for highthroughput molecular profiling of tumor specimens. Nat Med 1998;4:844-7. 9 Motzer RJ, Russo P. Systemic therapy for renal cell carcinoma. J Urol 2000:163:408-17. 